\title{
O \\ O LHARES \\ REVISTA DO DEPARTAMENTO DE EDUCAÇÃO- UNIFESP \\ Formação docente e (re)elaboração do ensino de Matemática no âmbito do PIBID: o uso de jogos como estratégia metodológica
}

Francisco José de Lima Instituto Federal de Educação, Ciência e Tecnologia do Ceará - Campus Cedro franciscojose@ifce.edu.br

Bruna Maria Vieira Gonçalves Instituto Federal de Educação, Ciência e Tecnologia do Ceará - Campus Cedro brunavieira1@outlook.com

\section{RESUMO}

As discussões acerca da formação inicial e prática docente são sempre muito latentes, considerando a complexidade dos processos de ensino e de aprendizagem e o papel desempenhado pelo professor no contexto educacional. $O$ presente artigo tem como objetivo refletir sobre a importância do Programa Institucional de Bolsas de Iniciação à Docência - PIBID para a constituição da práxis docente, vislumbrando a (re)elaboração do ensino de Matemática, com ênfase na utilização de jogos como estratégia metodológica. Para tanto, o estudo de abordagem qualitativa, recorreu a revisão bibliográfica e ao levantamento de estratégias de ensino, desenvolvidas por um grupo bolsistas vinculados ao PIBID/Subprojeto Matemática do IFCE campus Cedro. Nos limites desse artigo é discutida a utilização de jogos como possibilidade metodológica para ensinar e aprender Matemática básica. O estudo mostra-se relevante pela possibilidade de repensar o ensino de Matemática e fortalecer as discussões acerca da formação inicial do professor, tendo o PIBID como pano de fundo. Constatou-se que os jogos foram utilizados como recursos didáticos para trabalhar conteúdos da Matemática Básica, como as quatro operações fundamentais, em virtude do déficit de aprendizagem dos alunos no que tange a esses conhecimentos. Conclui-se que as ações desenvolvidas pelos bolsistas no âmbito do PIBID podem contribuir para a (re)elaboração do ensino de Matemática, por ser um espaço de reflexão e experiência de práticas docentes, que fortalece as licenciaturas e a formação inicial do professor.

Palavras-chave: Ensino de Matemática; Metodologia; Prática de Ensino.

\section{Teacher training and (re)elaboration of mathematics teaching within the PIBID: the use of games as a methodological strategy}




\section{ABSTRACT}

Discussions about initial education and teaching practice are always very latent, considering the complexity of teaching and learning processes and the role played by teachers in the educational context. This article aims to reflect on the importance of the Institutional Program of Teaching Initiation Scholarships - PIBID for the constitution of the teaching praxis, envisioning the (re)elaboration of mathematics teaching, with emphasis on the use of games as a methodological strategy. Therefore, the qualitative study used the literature review and the survey of teaching strategies developed by a group of scholarship holders linked to the PIBID/Mathematical Subproject of the IFCE campus Cedro. Within the limits of this article will be discussed the use of games as a methodological possibility to teach and learn basic mathematics. The study is relevant due to the possibility of rethinking mathematics teaching and strengthening discussions about the initial teacher's education, with PIBID as a background. It was found that the games were used as didactic resources to work basic mathematics contents, such as the four fundamental operations, due to the students' learning deficit regarding this knowledge. It is concluded that the actions developed by the scholarship holders within the scope of the PIBID can contribute to the (re)elaboration of mathematics teaching, because it is a space for reflection and experience of teaching practices, which strengthens the undergraduate and initial training of the teacher.

Keywords: Mathematics teaching; Methodology; Teaching Practice.

\section{Introdução}

Nos contextos educacional e escolar é recorrente tratar sobre a relevância do conhecimento matemático e suas potencialidades no processo de formação para a cidadania. Embora seja comum abordar a presença da Matemática no cotidiano das pessoas, ainda se observa muitas dificuldades em compreender essa relação e muitos alunos parecem indiferentes, não reconhecendo essa perspectiva e, ainda, demonstram resistência quanto aos processos de ensino e de aprendizagem desse componente curricular.

Quanto ao ensino de Matemática, é importante salientar que a prática docente desenvolvida em sala de aula tem reforçado a ideia de uma ciência abstrata e pronta, com predominância de métodos tradicionais e ênfase na memorização (BAUMGARTEL, 2016). Assim, parece urgente despertar para a (re)elaboração do ensino de Matemática, a partir do fortalecimento efetivo da formação inicial de professores em contexto de práticas, a fim de oportunizar aprendizagem docente e desenvolvimento de estratégias metodológicas.

Com o advento da Educação Matemática, movimento internacional desencadeado no Brasil no final da década de 1970, compreendido como "um campo de ensino e de pesquisa" (ZAIDAN et al., 2010, p.1), foi colocado no centro do debate as tendências em Educação Matemática, que apontaram novas possibilidades de abordagem para o ensino de matemática, ganhando força a modelagem matemática, a resolução de problemas, a utilização de Tecnologias da Informação e Comunicação - TIC e os jogos matemáticos.

Essa nova concepção de ensino de Matemática e essa necessidade de (re)formulálo parece exigir ainda mais dos cursos de licenciatura, haja vista que os futuros professores, aparentemente, não estão preparados para as mudanças desejadas, uma vez que a formação inicial esbarra na complexidade da profissão e a dicotomia entre teoria e prática ainda se faz presente nas licenciaturas, acarretando em uma formação deficitária. Conforme Fiorentini et al. (2002) dentre os problemas que emergem na formação dos professores 
estão, a desarticulação entre teoria e prática e o excesso de formalização nas disciplinas específicas, que distancia ainda mais os licenciandos da realidade escolar, na educação básica. Para os autores a reflexão e a investigação constituem o percurso formativo docentes e precisam fazer parte desse processo.

Quanto ao fazer docente e as possibilidades metodológicas, como reflexo dessa formação inicial e frente a multiplicidade das tendências em Educação Matemática, Fiorentini (1995) concluiu ser necessário, que os futuros professores, conheçam essas tendências em seu sentido completo, mediante estudo teórico que possibilite buscar suas raízes e origens, para que possam desenvolvê-las efetivamente em sala de aula.

Diante do exposto, chama-se atenção para o Programa Institucional de Bolsas de Iniciação à Docência, PIBID, criado com a finalidade de fomentar e valorizar a formação inicial e tem como base legal a Lei $n^{\circ}$ 9.394/1996, a Lei 11.273/2006 e o Decreto $n^{\circ}$ 7.219/2010. O programa possibilita aos futuros professores a inserção nas escolas, na condição de bolsistas, oportunizando o planejamento e desenvolvimento de ações metodológicas em sala de aula, bem como, maior aproximação entre a educação básica e o ensino superior e constitui-se como espaço de reflexão (BRASIL, 2016).

Nesse sentido, o estudo foi norteado pela seguinte questão: quais as implicações do PIBID para a constituição da prática docente, no contexto da formação inicial, a fim de viabilizar o processo de planejamento e (re)elaboração do ensino de Matemática?

$O$ presente trabalho justifica-se pela necessidade de (re)pensar o ensino de Matemática e o fazer docente. Por conseguinte, considera-se a formação inicial um percurso determinante para que tais transformações possam acontecer, uma vez que os professores desempenham papel essencial nessa (re)elaboração do ensino, mediante o exercício de sua prática em sala de aula. Acredita-se que refletir e discutir sobre o referido tema pode conduzir a ações que impulsionem possíveis mudanças, possibilitando assim, aprendizagem matemática. Compreende-se que a discussão sobre alternativas para ensinar não está dissociada do processo formativo do professor, depreendido aqui como pressuposto determinante para a efetivação da prática em sala de aula.

O estudo, portanto, tem como objetivo refletir sobre a importância do PIBID para a constituição da práxis docente, vislumbrando a (re)elaboração do ensino de Matemática, com ênfase na utilização de jogos como estratégia metodológica.

\section{Metodologias de ensino de Matemática: possibilidades e desafios no contexto da formação inicial}

O quadro branco, o pincel, o apagador e o livro didático parecem não ser mais suficientes para a promoção de uma aprendizagem, verdadeiramente, efetiva e significativa. $\mathrm{Na}$ tentativa de tornar o conhecimento matemático atrativo e acessível aos alunos e (re)significá-lo, os professores parecem sentir a necessidade de inovar em sala de aula e assim, buscam novos métodos e recursos de ensino. Silva (2005, p. 10) afirma que

As dificuldades encontradas pelos estudantes quanto à aprendizagem da Matemática não são motivadas exclusivamente pelas características da disciplina. Essas dificuldades são reflexos, também, da capacitação deficitária dos professores, da busca inadequada de novos recursos pedagógicos e da falta de contextualização. 
Cabral (2006) considera que o fato de a Matemática ser tão temida pelos alunos se deve ao método de ensino empregado em sala de aula. $O$ autor pontua um roteiro, seguido por muitos professores nas escolas, característico de um ensino tradicional: o conteúdo estudado é exposto com o auxílio do quadro branco, o aluno, por sua vez, transcreve em seu caderno essas informações, seguidas pela resolução de exercícios de fixação, sem que tenham a possibilidade de pensar, criar e aprender, efetivamente. Para o autor, geralmente,

[...] a matemática aplicada nas escolas não oferece ao aluno a oportunidade de se expressar e participar do processo de construção do conhecimento, o exclui de uma possível aplicabilidade destes conteúdos em sua vida fora da escola (CABRAL, 2006, p. 12).

Desse modo, defende-se que é importante refletir sobre o papel dos cursos de licenciatura como espaços responsáveis pela formação inicial docente. Se os professores não são frutos de uma formação eficaz e renovada, seriam eles capazes de criar atividades diferenciadas, que desenvolvam o raciocínio e a discussão?

Um estudo realizado por Fiorentini e Oliveira (2013), aponta que a formação matemática nas licenciaturas deve vislumbrar a prática na escola básica e, portanto, não pode assumir uma estrutura de bacharelado, privilegiando a formalidade e o rigor procedimental das disciplinas. Sinalizam que a pesquisa pode ser o caminho para (re)pensar o ensino da Matemática e assim, renovar a prática em sala de aula. Os autores concluem que

Não se trata, portanto, de apenas mudar ementas ou reestruturar grades
curriculares. São importantes os conteúdos da matemática superior que compõem
as disciplinas de formação matemática da licenciatura, pois amplia-se, assim, a
visão dos futuros professores acerca da matemática como campo de conhecimento.
Mas, é necessário adotarmos posturas que apontem para uma visão mais
integradora do curso, sem deixar de aprofundar, numa perspectiva multirrelacional,
epistemológica e histórico-cultural, o conteúdo específico (FIORENTINI; OLIVEIRA,
2013, p. 935).

Assim, não se pode perder de vista que a licenciatura em Matemática deve formar professores, não para trabalhar puramente com números, mas principalmente com alunos, que carregam consigo certa subjetividade. Se a Matemática é exata, a sala de aula não é. As convicções sobre o ensino de Matemática se renovam, apontando uma nova visão sobre o papel da escola, do docente e do aluno, no processo de ensino e de aprendizagem. Ainda que existam deficiências na prática pedagógica do professor, as inquietações e debates sobre o tema são fundamentais para o amadurecimento dessas novas ideias e transcendem a precarização da formação inicial.

A seguir, são apresentadas algumas considerações acerca da utilização de jogos, como estratégia metodológica para o ensino de Matemática, suas potencialidades e limites.

\section{Utilização de Jogos Matemáticos como Metodologia de Ensino}

Com o avançar dos anos escolares a Matemática aparentemente ganha maior rigorosidade, de modo que as aulas parecem intimidar os alunos, que tendem a demonstrar maior resistência ao estudo da disciplina, como constataram Mendes e Carmo (2014). A utilização de jogos no ensino de Matemática, portanto, surge como um resgate à ludicidade, 
com o despertar para a imaginação, a criação e o desenvolvimento do raciocínio lógico dos discentes. Consequentemente, podem ser uma ferramenta para despertar maior interesse dos estudantes pelo conhecimento matemático (BRAZ; MIRANDA; BARBOSA, 2018).

De acordo com Pereira e Kieckhoefel (2018, p. 173) "os jogos são caracterizados pela existência de regras, buscam atingir objetivos próprios e ocorrem em uma realidade própria (espaço e tempo)". Baumgartel $(2016$, p. 3) ressalta que

\begin{abstract}
O jogo pode ser utilizado como uma forma de entretenimento e de socialização, mas também pode ter como finalidade ou mesmo consequência o desenvolvimento de habilidades e de conceitos, uma vez que sua utilização no processo de ensino e de aprendizagem pode ser um facilitador.
\end{abstract}

Com a aplicação de jogos no ensino de Matemática os alunos têm a possibilidade de formular hipóteses e estratégias, para que assim possam chegar a solução desejada, bem como têm a oportunidade de desenvolver o raciocínio lógico. $O$ trabalho em equipe ou mesmo individual, a necessidade de argumentação, iniciativa e concentração, também são fatores que podem agregar muito ao processo de aprendizagem (MENOR FILHO, 2018).

Menezes e Muzatti (2016, p. 64) ao pesquisarem acerca dos jogos digitais incorporados ao ensino de Matemática, destacam algumas vantagens quanto a sua utilização e defendem que:

Os jogos levam os jogadores para um estado de intensa concentração, onde a vontade de vencer promove o desenvolvimento de habilidades. Eles fazem com que o aluno necessite tomar decisões e os expõem a níveis crescentes de desafios possibilitando a aprendizagem pela variedade de estratégias, resolução de problemas, raciocínio dedutivo e memorização. Contribuem, ainda, para maior socialização e ao trabalho em equipe.

Orth e Melo (2016, p. 155) defendem que, além de estimular o raciocínio lógico, "trabalhar com jogos lúdicos, significa aguçar [...] para uma nova construção de conhecimentos, favorecendo a vivência de situações de forma crítica e que aprendam a lidar uns com os outros, provocando-os a novos desafios construtivistas e concretos". Compreende-se que tal proposta é significativa para os discentes, uma vez que, existe uma visão muito engessada no que se refere ao estudo da Matemática, com um ensino predominantemente abstrato, no qual o aluno "copia o que está no quadro em seu caderno e, em seguida, procura fazer exercícios aplicando um modelo de solução que foi apresentado anteriormente pelo professor" (CABRAL, 2006, p. 9).

Tal estratégia de ensino, contudo, não deve ser resumida a uma simples brincadeira despretensiosa, uma vez que os objetivos da aula devem ser bem definidos, com finalidade na aprendizagem significativa. Dessa forma, Pereira e Kieckhoefel $(2018$, p. 183) alertam que "[...] para que tenham resultados positivos, é fundamental que os jogos sejam planejados no contexto em que se pretende utilizá-los. [...] Desde que planejados com objetivos definidos e regras claras, eles são aliados à educação Matemática".

Corroborando com os autores supracitados, Menezes e Muzatti (2016, p.55) afirmam que "é necessário um processo de intervenção pedagógica para que o jogo não perca seu objetivo principal que é a fixação do conteúdo abordado". Os autores concluem que: 
[...] quando os jogos são utilizados com o desvio desse propósito, corre-se o risco de dar ao jogo um caráter puramente aleatório, onde os alunos jogam sem saber qual o real objetivo do jogo, gastando tempo e energia sem propósito, além de sacrificar outros conteúdos que poderiam estar sendo trabalhados na sala de aula (MENEZES; MUZATTI, 2016, p. 64).

Entende-se que essa intervenção pedagógica só é possível se o docente se apropriou do recurso didático empregado em sala de aula e está consciente de sua práxis. É necessário que os alunos sejam orientados e estimulados a pensar e formular hipóteses para solucionar os problemas propostos, de modo que tais "intervenções estimulem neles novas reflexões, para que mobilizem os saberes já construídos e possam construir ou (re) significar os já existentes" (SILVA; MIRANDA; PIETROPAOLO, 2020, p. 416).

Fiorentini e Miorim (1990, p. 3) alertam que, "a simples introdução de jogos ou atividades no ensino da Matemática não garante uma melhor aprendizagem desta disciplina". Para Silva, Miranda e Pietropaolo (2020, p. 401) "[...] é preciso ter clareza da necessidade, mais do que a motivação [...]". Compreende-se, portanto, que o professor ao optar pela utilização de tais recursos didáticos deve estar consciente da escolha do material, como utilizado, quando, por quê e para quê, de modo que a sua aula não se resuma a um momento recreativo, sem finalidade na aprendizagem significativa, visto que esses mecanismos de ensino não são autossuficientes.

Pensar novas formas de ensinar e aprender Matemática, tendo em vista que existe uma visão muito superficial sobre essas novas propostas metodológicas, seja por parte dos alunos ou mesmo dos professores, torna ainda mais desafiador a iniciativa de fazer diferente em sala de aula. Assim, as práticas que possibilitam uma mudança e uma reconfiguração do espaço escolar não devem ser banalizadas ao ponto de não conduzirem uma aprendizagem satisfatória daquilo que está sendo estudado.

Entende-se, portanto, que a oportunidade de aprender de uma forma mais dinâmica e descontraída pode contribuir não só para aprendizagem, mas para desconstruir conceitos culturalmente construídos quanto as aulas de Matemática, predominantemente expositivas.

Parece ainda mais necessário que os alunos possam assumir uma postura protagonista como seres pensantes. As salas de aula parecem ser constituídas pelo silêncio, no que tange a participação e interação do grupo, diante do que é estudado. Em contrapartida, o barulho ensurdecedor das conversas paralelas, em salas superlotadas, evidencia o quão desinteressante é estar sentado, ouvindo passivamente informações, aparentemente, sem sentido. Ao pensar a possibilidade de aprender Matemática "brincando", o barulho passa a existir em uma nova configuração, considerando-se que não existe aprendizagem no silêncio absoluto.

\section{Procedimentos Metodológicos}

Ancorada na perspectiva da pesquisa analítica descritiva, com abordagem qualitativa, (BOGDAN; BIKLEN, 1994) e adotando como procedimentos para a coleta de dados a pesquisa bibliográfica e documental (GIL, 2002), a presente investigação, centra-se na discussão da (re)elaboração do ensino de Matemática no contexto do PIBID, Subprojeto vinculado ao curso de Licenciatura em Matemática de uma Instituição Federal de ensino que desenvolve atividades do Programa desde o edital CAPES/DEB nº 02/2009. 
Com a vigência do edital n 61/2013, o Subprojeto/PIBID Matemática da unidade, constituiu-se por 30 bolsistas de iniciação à docência (ID), 03 professores supervisores (professores de Matemática) e 02 coordenadores de área (um da Área Específica e outro da Área Pedagógica), de forma que o grupo de licenciandos dividia-se em equipes de dez, distribuídos em escolas da rede pública estadual de três cidades do interior do Ceará.

O Subprojeto PIBID/Matemática, tinha como foco de atenção a formação inicial e continuada do professor, a partir de encontros semanais para estudo, discussão e planejamento de atividades sobre o estudo de Funções e Geometria, com ênfase na Resolução de Problemas, bem como o cotidiano escolar e da sala de aula, a partir das prescrições que estruturam e fundamentam a educação no contexto educacional brasileiro.

Quanto aos encaminhamentos para desenvolvimento da pesquisa, inicialmente foi realizado uma revisão bibliográfica acerca da utilização de jogos enquanto metodologia de ensino de Matemática, em periódicos online ou revistas acadêmicas e científicas. Subsidiaram a discussão teórica autores como, Orth e Melo (2016), Menor Filho (2018), Menezes e Muzatti (2016) e Baumgartel (2016).

Posteriormente, foi realizado um levantamento das atividades desenvolvidas pelos bolsistas ID, de modo a discutir as estratégias de ensino empregadas na ambiência do Programa, depreendendo-as como possibilidade de (re)elaboração do ensino de Matemática. O acesso a tais ações metodológicas se deu a partir dos dados disponíveis no Blog do Subprojeto PIBID do IFCE campus Cedro, considerando-se os registros de 2014 a 2017 e priorizando-se as metodologias inovadoras, norteadas pelos princípios da Educação Matemática, como as propostas de aulas mediante a resolução de problemas, utilização de jogos e uso de softwares educativos.

Quanto à análise dos dados, os resultados da pesquisa foram estruturados em três eixos de discussão, mediante as unidades de estudo mais exploradas. Assim, com o levantamento dos dados coletados no Blog, foram identificados os conteúdos recorrentes, trabalhados pelos bolsistas junto aos alunos atendidos pelo Programa nas escolas básicas e a metodologia de ensino empregada no desenvolvimento das aulas, resultando na elaboração de três eixos de análise: 1) Utilização de jogos como possibilidade metodológica para ensinar e aprender Matemática básica, 2) O GeoGebra como recurso metodológico para o ensino de Funções, e 3) Estudo de Geometria e perspectivas de intervenções no desenvolvimento da aprendizagem matemática.

Dentre as dificuldades enfrentadas no levantamento e análise dos dados, pontua-se a superficialidade das informações fornecidas pelo blog, uma vez que, algumas postagens traziam apenas registros fotográficos das aulas, sem detalhar o conteúdo programático, a estratégia de ensino empregada ou os objetivos e resultados obtidos, assim como os registros de possíveis desafios enfrentados para a realização da atividade.

Nos limites desse artigo apresentado o primeiro eixo, de modo a analisar e discutir sobre a utilização de jogos matemáticos em sala de aula como estratégia metodológica e possibilidade de (re)elaboração do ensino de Matemática. Aborda ainda acerca do impacto do Programa na constituição da prática docente do licenciando. 
Os resultados e discussões levam em consideração os dados coletados e analisados a partir do Blog PIBID IFCE campus Cedro, mas também dialogam com experiências vivenciadas como bolsista do Programa.

\section{Utilização de jogos como possibilidade metodológica para ensinar e aprender Matemática Básica}

Os rumos da educação brasileira são orientados por prescrições e diretrizes curriculares que norteiam o percurso a ser seguido, sem perder de vista as contribuições de estudos e pesquisas que realçam expectativas por melhorias em relação aos resultados e a qualidade do ensino. Em Educação Matemática, as possibilidades de ações e adaptações metodológicas apontam para a necessidade de se (re)pensar a prática de ensino. Nessa perspectiva entende-se que o PIBID é um espaço formador que possibilita aos futuros professores vivenciar a sala de aula na prática, planejar e experimentar métodos para o ensino da Matemática.

A partir do levantamento realizado no Blog do PIBID IFCE campus Cedro, constatou-se que os conteúdos mais recorrentes, abordados pelos bolsistas, foram o estudo de Funções e Geometria. Além desses, aqueles referentes à Matemática Básica, como as quatro operações fundamentais, frações, potenciação e radiciação, também foram priorizados pelos licenciandos, mesmo não sendo um foco do Programa, considerando as necessidades e lacunas na aprendizagem de estudantes da escola básica.

Assim, é preciso ressaltar que apesar de a Matemática ser uma ciência hipotéticodedutiva e suas demonstrações se apoiarem em um sistema de axiomas e postulados, é de fundamental importância também considerar o papel heurístico das experimentações na aprendizagem da Matemática (BRASIL, 2017).

Nesse sentido, em função do déficit de aprendizagem dos alunos no que tange a esses conteúdos, foi possível observar que os bolsistas ID, com anuência do professor supervisor, acabam tendo como foco de atenção, também, as operações matemáticas fundamentais. Dito isso, percebe-se ainda que, a compreensão da realidade escolar influencia e conduz as adaptações necessárias para definir o que será estudado e quais ações de intervenção deverão ser propostas pelos licenciandos.

Acredita-se que o domínio dessas operações básicas contribui para a compreensão de assuntos posteriores, os quais exigirão muito mais que cálculos e assimilação de fórmulas. Visto que os conteúdos matemáticos mostram-se rigorosamente relacionados, um aluno que não compreende e domina os seus conceitos básicos e operações fundamentais, não depreende e, consequentemente, sua aprendizagem e desenvolvimento matemático tendem a não acontecer.

Uma das críticas mais frequentes quanto às avaliações externas, por exemplo, reside no fato de que essas cobram habilidades que os alunos ainda não tiveram oportunidade de desenvolver, haja vista que, se nem mesmo conhecem a temida tabuada, tampouco conseguirão solucionar uma situação-problema, que não só exige deles o domínio das quatro operações como também, leitura e interpretação. As escolas e os professores, portanto, vivem o dilema do nivelamento, de forma que buscam minimizar as 
dificuldades apresentadas pelos alunos, a fim de consolidar a base do saber matemático, que parte do domínio das quatro operações básicas.

Diante das dificuldades apresentadas pelos alunos, fator que motivou a decisão de abordar esses conteúdos matemáticos básicos, pode-se inferir que os jogos utilizados pelos bolsistas do Programa, classificam-se de acordo com Cabral (2006, p. 30), como jogos de treinamento, pois são empregados "quando o professor percebe que alguns alunos precisam de reforço num determinado conteúdo e quer substituir as cansativas listas de exercícios".

$\mathrm{Na}$ tentativa de abordar os conteúdos de uma forma mais descontraída, mas não menos importante, os bolsistas ID utilizaram os jogos matemáticos, de modo a construir um espaço menos rigoroso, haja vista que muitos alunos se sentem constrangidos por não conseguirem realizar cálculos considerados simples, como os que constituem a tabuada.

Menezes e Muzatti (2016, p. 54) defendem que a utilização de jogos no ensino da Matemática é importante, pois é uma forma de "superar um ensino pautado em decorar conteúdos e regras sem qualquer aplicação por conhecimentos mais significativos que despertam o interesse dos estudantes". Nessa mesma perspectiva, Orth e Melo (2006), afirmam que o ensino de matemática, pautado em métodos tradicionais, está praticamente defasado e não propicia uma aprendizagem adequada.

Pode-se observar que quando se propõe a utilização de jogos, é importante reforçar que a ideia não é transformar a aula em um momento recreativo. A finalidade não é a brincadeira em si, mas a oportunidade que o discente tem de tomar decisões, criar estratégias, bem como amadurecer sua percepção acerca do conteúdo estudado e assim, (re)significá-lo. Compreende-se que a superação do ensino tradicional parte, também, desse olhar para os alunos, assumindo-os como seres pensantes e protagonistas no processo de (re)construção do conhecimento.

Talvez este seja um dos desafios para o professor ao adotar essa estratégia de ensino: desconstruir nos discentes a compreensão despretensiosa quanto à utilização de jogos nas aulas de Matemática e entendê-la como ação potencial para o desenvolvimento da aprendizagem. Importante destacar, ainda, que essa visão banal quanto a referida estratégia de ensino, parece colocá-la como simples e que não exige atenção. O que não é verdade. Assim, como qualquer outra metodologia a ser empregada em sala de aula, a utilização de jogos parte de objetivos bem definidos e precisam ser escolhidos cuidadosamente. Fiorentini e Miorim (1990, p. 3) alertam que

[...] o professor não pode subjugar sua metodologia de ensino a algum tipo de material porque ele é atraente ou lúdico. Nenhum material é válido por si só. Os materiais e seu emprego sempre devem estar em segundo plano. A simples introdução de jogos ou atividades no ensino da Matemática não garante uma melhor aprendizagem desta disciplina.

Nesse sentido, não se pode perder de vista o processo de (re)construção do conhecimento matemático. Assim, o emprego de metodologias inovadoras não é garantia de aprendizagem significativa, se professores e alunos não estiverem conscientes de seu potencial. É preciso construir uma cultura cuidadosa e (re)elaborada em relação a esse aspecto. Essa cultura diz respeito ao despertar para o novo, desprendendo-se de 
concepções que banalizam as propostas de ensino que fogem do método tradicional, a exemplo do uso de jogos matemáticos.

Desse modo, a formação do professor deve ser o pano de fundo para essa (re)elaboração, uma vez que, as licenciaturas precisam assumir o papel que lhe compete, de formar profissionais capazes propor novas abordagens de ensino e aprendizagem, mediante suporte teórico, mas também prático, (re)pensando de novas metodologias, que conduzam um fazer docente consciente e uma aprendizagem com significado. É fundamental que o professor esteja sempre atento para a construção de pontes que liguem o conhecimento científico e formal aos estudantes.

Pensando nisso, destacam-se as ações formativas realizadas pelo PIBID, destinadas aos bolsistas, com o intuito de ampará-los em sua atuação nas escolas parceiras de educação básica. Ressaltam-se os momentos de capacitação, como: a oficina referente ao uso de material concreto, com proposta de atividade prática no ensino de Geometria, bem como as oficinas, "O uso da Teoria dos Registros de Representação Semiótica (TRRS) como perspectiva teórica e metodológica para o ensino e a aprendizagem da Matemática - Introdução ao GeoGebra", "Introdução ao GeoGebra" e "Comunicação Audiovisual para Produção de Vídeo-Aulas". Destacam-se também os estudos propostos sobre as "Teorias de ensino e metodologia de pesquisa em Matemática" e "Situações Didáticas com Resolução de Problemas".

Tais ações vão muito além do estudo sobre utilização de jogos matemáticos em sala de aula, mas são fundamentais para fornecer, aos futuros professores, conhecimentos teóricos que venham subsidiar suas ações nas escolas parceiras e com isso permitam orientá-los quanto as escolhas metodológicas que podem ser realizadas. As reuniões semanais representam, portanto, um planejamento coletivo, que ajuda a direcionar o fazer docente e a tomada de decisões, a fim de minimizar as dificuldades, inevitáveis, que surgem no desenvolvimento das atividades.

Reafirma-se que os jogos não podem ser confundidos com brinquedos e que, se são facilitadores e não são autossuficientes, também não podem substituir o professor, fato que exige dos docentes a apropriação desse método de ensino. Ressalta-se, portanto, a importância do docente como mediador do saber, o elo que conduz os processos de ensino e de aprendizagem e a formalização do conhecimento, haja vista que "não é o jogo que trabalha a matemática, mas a intervenção pedagógica que se faz nele" (MENOR FILHO, 2018, p. 53).

Merece destaque a oficina desenvolvida por bolsistas sobre o estudo de frações, intitulada "Aprendendo frações com o uso de material lúdico". A proposta chama atenção pela variedade de recursos utilizados no decorrer das aulas e a organização do conteúdo abordado, partindo do regate histórico das frações e sua presença no cotidiano.

A partir dos registros disponibilizados no Blog PIBID IFCE campus Cedro do Subprojeto Matemática, verificou-se que durante as aulas foram trabalhadas, a história do desenvolvimento das frações, definição, propriedades, técnicas de leitura, representação na reta numérica, comparação de frações, técnicas de transformações de números mistos em frações impróprias e vice-versa e técnicas de determinação das frações geratrizes das dízimas periódicas. 
Para tanto, foram utilizados alguns recursos didáticos como uma receita de bolo, um experimento envolvendo líquido disposto em recipientes e também o auxílio dos discos de frações. Foi usado ainda o GeoGebra e aplicado um jogo de cartas, Truck, a fim de reforçar o estudo sobre comparação de frações. A postagem da aula, presente no Blog, não detalha sobre como funciona o jogo, suas regras e número de participantes. Também não relata sobre os resultados alcançados ou impressão dos discentes sobre a dinâmica das aulas.

Contudo, mediante os registros fotográficos dos momentos de aula, observou-se a participação dos alunos na manipulação dos objetos, com um olhar curioso, de modo a expressarem alegria em (re)descobrir a Matemática, a partir dessas novas propostas metodológicas. Os bolsistas ID, por sua vez, tiveram a oportunidade de colher os frutos daquilo que foi planejado, mediante a aprendizagem e satisfação dos alunos durante a aula, o que parece impulsionar seu desenvolvimento profissional e incentivá-los a serem diferentes e fazerem a diferença. À medida que (re)significam a Matemática para os alunos, com o uso de diferentes estratégias de ensino, parecem (re)significá-la para si mesmos. E quando conseguem atingir, positivamente, os alunos por meio de sua práxis renovada, parecem se encontrar na profissão e, com isso, reafirmar sua escolha pela docência.

Além do jogo de cartas Truck empregado nessa oficina, outros jogos foram utilizados pelos bolsistas no desenvolvimento de suas aulas, em outros momentos, a saber: bingo, corrida Algébrica, dominó, trilha das quatro operações, batata quente, jogo da memória, jogo do sobe e desce, trilha do desafio, jogo de ludo, batalha geométrica e jogo das senhas. Algumas vezes os monitores do PIBID optaram por construir os jogos com os alunos, com a intenção de envolvê-los na proposta de aula, incentivando-os a participar das atividades. Para Menor Filho, (2018, p. 55), o momento de confecção dos jogos pelos alunos pode ser um momento propicio para a construção de conceitos matemáticos importantes, bem como pode favorecer a socialização dos discentes. Para o autor, esse "procedimento envolve o aluno em um movimento contínuo e aprofundado de suas bases teóricas" e constitui-se como um "caminho para apender Matemática por meio de jogos".

Ao proporcionar oportunidades de produção de atividades aos estudantes para trabalharem com conceitos e termos matemáticos, também estamos contribuindo para que eles se tornem mais confiantes na disciplina e que os mesmos se engajem no material aprendido mais profundamente. A reflexão sobre a matemática que estão aprendendo leva os discentes a importantes avanços cognitivos e afetivos. Eles adquirem mais controle sobre sua aprendizagem e desenvolvem critérios para coordenar seu processo. Essa capacidade de controlar e fiscalizar o processo do aprendizado causa sentimentos de realização. Os alunos também desenvolvem confiança e motivação para fazer e entender matemática (MENOR FILHO, 2018, p. $56)$.

Em se tratando do planejamento das aulas, elaboração de atividades e construção de materiais, existia uma preocupação em cativar os alunos, em aproximá-los do conhecimento matemático, em experimentar e vivenciar tais experiências com o grupo, de uma maneira que pudessem ajudar os estudantes em seus anseios, dúvidas e particularidades. Assim, os planejamentos partiam da compreensão da realidade das instituições parceiras. Cabral (2006, p. 29), afirma que esse momento de organização da aula para utilização de jogos educativos é necessário, pois permite "que o professor possa 
explorar todo o potencial dos jogos, processos de solução, registros e discussões sobre possíveis caminhos que poderão surgir".

Em cada registro, ficou claro a dedicação e cuidado com o qual foram pensadas as aulas. Não dizia respeito apenas à obrigação de cumprir com o cronograma do Programa e ministrar aulas, em virtude do recebimento da bolsa, mas o comprometimento e preocupação com cada aluno atendido, o desejo de ensinar, mas, sobretudo de aprender. Inspirar e sentir-se professor. Tal fato não é uma garantia de promoção de aprendizagem significativa, mas sinaliza a busca por iniciativas que viabilizem mudanças no processo de ensino de Matemática.

As análises realizadas, a partir dos apontamentos do Blog não permitem aprofundar as discussões no que tange os resultados obtidos com as aulas, contudo os recursos didáticos e metodologias empregadas, apontam para a tentativa de (re)elaboração do ensino de Matemática.

\section{Considerações Finais}

Ao refletir sobre a (re)elaboração do ensino de Matemática no contexto do PIBID e a utilização de jogos como estratégia metodológica, observando seus desafios e possibilidades, esse estudo não tem a proposta de simplificar esse processo, até porque não é um percurso simples. No contexto educacional, muito se fala sobre a necessidade de mudanças, mas pouco parece ser feito para alcançar transformações, quando a saída mais aparente tem sido buscar culpados para o fracasso educacional. Ora é o sistema, ora a ausência da família, a indisciplina e desinteresse dos alunos ou a ineficiência da formação inicial dos professores. A verdade é que há muito a ser feito na expectativa de melhor desenvolver os processos de ensino e de aprendizagem.

Assim, embora se reconheça as lacunas existentes na formação inicial do professor de Matemática, é essencial que esforços sejam empreendidos para que essas assimetrias sejam equacionadas ou superadas a cada dia. Políticas e programas que incentivem e fortaleçam a formação de professores, podem contribuir para a melhoria dos processos formativos para a docência. Essas ações, ainda que não abarquem todos os licenciandos, abrem espaços para o debate e possibilitam múltiplas reflexões sobre a docência e o campo educacional.

Nessa pesquisa, enfatizou-se o uso de jogos como estratégia metodológica, a fim de reconhecer novas possibilidades de ensino e aprendizagem de Matemática, haja vista que "o diferente não se manifesta, necessariamente, no novo que, por sua vez, não surge, necessariamente, como diferente [...]. Sustentamos que criar, também, surge como recriar com o que temos nas mãos, reinventando-o, abrindo caminhos. E isso sempre se faz [...]" (BAMPI; CAMARGO, 2016, p. 962). Assim, inovar pode ser mais simples do que se imagina.

Parece importante descontruir a ideia de que o diferente é obrigatoriamente inédito e reconhecer que o dito inovador pode não assumir esse caráter de inovação. Assim, a mudança talvez parta da ação de enxergar novos caminhos metodológicos a partir do que se tem à disposição, de modo que se defende não apenas a necessidade de criar, mas também de recriar. Com isso, a (re)elaboração do ensino parte não só do olhar para o 
protagonismo do aluno e sua autonomia na construção do conhecimento, mas também entender o professor enquanto protagonista de suas práticas, capaz de pensar e criar meios que oportunizem a aprendizagem efetiva.

A partir dessa pesquisa, pode-se concluir que o trabalho desenvolvido pelos bolsistas ID, sob a orientação de professores supervisores e coordenadores de área do PIBID em instituições de ensino da rede estadual, pode conduzir a (re)elaboração do ensino de Matemática, visto que sugerem propostas de ensino que transcendem práticas e métodos usualmente utilizados em aulas de Matemática, sugerindo novas estratégias metodológicas, cuja expectativa é o desenvolvimento da aprendizagem matemática e a aprendizagem da docência.

Para além do contato com concepções, abordagens de tendências em Educação Matemática e emprego de métodos de ensino, o Programa é um espaço que enriquece a(s) licenciatura(s) no campo da pesquisa acerca da profissão do professor, sob uma óptica abrangente de reflexão e oxigenação do percurso formativo docente.

Não se pode perder de vista que os licenciandos ainda que estejam acompanhados por coordenadores de área e professores supervisores, também enfrentam dificuldades quanto à falta de recurso e tantas outras questões internas de cada escola atendida, que afetam o desenrolar de suas ações. Contudo, estão conscientes de que não podem negar aos estudantes o direito de aprender Matemática, pois os futuros professores têm a oportunidade de estarem imersos em um espaço formativo, pensando e discutindo sobre elementos e pressupostos do fazer docente.

Convêm reforçar que a utilização de jogos não se apresenta como uma solução única e infalível para a (re)elaboração do ensino de Matemática, mas como uma possibilidade de repensar as práticas de ensino e proporcionar aos alunos uma aprendizagem significativa. Portanto, ao optar pelo uso de jogos matemáticos o professor deve estar consciente de quando, por quê e para quê utilizá-los.

Também não se propõe abolir os métodos tradicionais de ensino, como as listas de exercício, pois essas têm sua importância no contexto de sala de aula, dado que nem todo conteúdo pode ser apresentado com a mesma dinâmica que outro. A crítica feita, diz respeito a predominância desses métodos convencionais, que apresentam uma Matemática distante dos alunos, fechada, rígida, excludente e desconectada da realidade.

Para tanto, é preciso fortalecer a formação inicial docente, de modo que essa ofereça o suporte teórico e prático, necessário para o exercício da profissão e de fato permita a mudança desejada no ensino. Além de, valorização do magistério, melhores condições de trabalho, investimentos e incentivos à formação continuada.

\section{Referências}

BAMPI, L. R.; CAMARGO, G. D. Didática dos Signos: ressonâncias na Educação Matemática contemporânea. Bolema, Rio Claro, v. 30, n. 56, p. 954-971, dez. 2016. Disponível em: <http://www.scielo.br/scielo.php?pid=S0103-636X2016000300954 \&script=sci_abstract \&tlng=pt>. Acesso em: 09 fev. 2018. 
BAUMGARTEL, P. O uso de jogos como metodologia de ensino da Matemática. In: Anais XX EBRAPEM, 2016, Curitiba. Disponível em: http://www.ebrapem2016.ufpr.br/wpcontent/uploads/2016/04/gd2_priscila_baumgartel.pdf. Acesso em: 13 set. 2020.

BOGDAN, R. C.; BIKLEN, S. K. Investigação qualitativa em educação. Tradução Maria João Alvarez, Sara Bahia dos Santos e Telmo Mourinho Baptista. Porto: Porto Editora, 1994.

BRASIL. Portaria n 46, de 11 de abril de 2016. Aprova o Regulamento do Programa Institucional de Bolsa de Iniciação à Docência. Brasília: MEC/CAPES, 2016.

BRASIL. Base Nacional Comum Curricular: Educação Infantil e Ensino Fundamental. Brasília: MEC/Secretaria de Educação Básica, 2017.

BRAZ, S. C.; MIRANDA, T. K.; BARBOSA, C. P. A utilização de jogos no ensino de Matemática: uma experiência com alunos do ensino médio. ForSCIENCE, Minas Gerais, v. 6, n. 1, p. 1-20, 2018. Disponível em: http://www.forscience.ifmg.edu.br/forscience/index. php/forscience/article/view/365. Acesso em: 13 set. 2018.

CABRAL, M. A. A utilização de jogos no ensino de Matemática. 2006. 52 f. Monografia (Graduação) - Curso de Matemática, Universidade Federal de Santa Catarina, Florianópolis, 2006. Disponível em: <http://www.pucrs.br/ciencias/viali/tic_litera tura/jogos/Marcos_

Aurelio_Cabral.pdf>. Acesso em: 21 mai. 2018.

FIORENTINI, D. Alguns modos de ver e conceber o ensino de Matemática no Brasil.

Revista Zetetiké, Campinas, v. 3, n. 4, p.1-38, 1995. Disponível em: https://periodicos. sbu.unicamp.br/ojs/index.php/zetetike/article/view/8646877/15035. Acesso em: 11 ago. 2018.

FIORENTINI, D.; OLIVEIRA, A. T. C. C. O lugar das Matemáticas na Licenciatura em Matemática: que Matemáticas e que práticas formativas? Bolema, Rio Claro, v. 27, n. 47, p. 917-938, 2013. Disponível em: <http://www.periodicos.rc.biblioteca.unesp.br/index.php/ bolema/article/view/8286/5867>. Acesso em: 12 jan. 2018.

FIORENTINI, D.; MIORIM, M. A.Uma reflexão sobre o uso de materiais concretos e jogos no Ensino da Matemática. Boletim SBEM, São Paulo, v. 4, n. 7, 1990. Disponível em:

http://www.pucrs.br/ciencias/viali/tic_literatura/jogos/Fiorentini_Miorin.pdf. Acesso em: 20 mai. 2018.

MENDES, A. C.; CARMO, J. S. Atribuições Dadas à Matemática e Ansiedade ante a Matemática: o relato de alguns estudantes do ensino fundamental. Bolema, Rio Claro, v. 28, n. 50, p. 1368-1385, dez. 2014. Disponível em: http://www.scielo.br/pdf/bolema/v28n50/ 1980-4415-bolema-28-50-1368.pdf. Acesso em: 11 jan. 2018.

MENEZES, A. L. J.; MUZATTI, Luciana Ap. Ferrarezi. Jogos no ensino de Matemática: o uso de aplicativos como estratégia de aprendizagem. Interface Tecnológica, Taquaritinga, v. 13, n. 1, p. 53-67, 2016. Disponível em: https://revista.fatectq.edu.br/index.php/interface tecnologica/article/view/125. Acesso em: 13 set. 2020.

MENOR FILHO, J. S. O ensino de Matemática e os jogos didáticos na sala de aula. Revista de Estudos de Gestão, Informática e Tecnologia, Itaquaquecetuba, v. 9, n. 1, p. 49-59, 2018. Disponível em: http://www.revista.fatecitaqua.edu.br/index.php/regit/article/view/REG IT9-A3. Acesso em: 13 set. 2020. 
ORTH, A. C.; MELO, C. L. O. Utilização dos jogos lúdicos como instrumento construtivista no ensino da Matemática. Ágora, Espírito Santo, v. 11, n. 22, p. 148-155, 2016. Disponível em: http://agora.ceedo.com.br/ojs/index.php/AGORA_Revista_Eletronica/article/view/237. Acesso em: 13 set. 2020.

PEREIRA, K.; KIECKHOEFEL, T. Reflexões acerca do uso de jogos no contexto educacional da Matemática. Ensino da Matemática em Debate, São Paulo, v. 5, n. 2, p. 170-185, 2018. Disponível em: https://revistas.pucsp.br/emd/article/view/38068. Acesso em: 13 set. 2020.

SILVA, A. F. G.; MIRANDA, M. S.; PIETROPAOLO, R. C. A utilização de jogos estratégicos como fonte para reflexão sobre o ensino de Matemática. Revista Paraense de Educação Matemática, Campo Mourão, v.9, n.18, p. 398-418, 2020. Disponível em: http://www. fecilcam.br/revista/index.php/rpem/article/view/2204/pdf_401. Acesso em: 16 set. 2020. SILVA, J. A. F. Refletindo sobre as dificuldades de aprendizagem na matemática: algumas considerações. Universidade Católica de Brasília, 2005. Disponível em: http://ww w.ucb.br/sites/100/103/TCC/22005/JoseAugustoFlorentinodaSilva.pdf. Acesso em: 10 nov. 2018.

ZAIDAN, S.; DAVID, M.M.S.; ARAÚJO, J.L.; GOMES, M.L.M.; FONSECA, M.C.F.R.F. Educação matemática. In: OLIVEIRA, D.A.; DUARTE, A.M.C.; VIEIRA, L.M.F. (Org.). Dicionário: trabalho, profissão e condição docente. Belo Horizonte: UFMG/Faculdade de Educação, 2010. CDROM. EDUCAÇÃO. Disponível em: https://www.gestrado.net.br/?p $\mathrm{g}=$ dicionario-verbetes\&id=405. Acesso em: 08 jan. 2020.

Recebido em: (27/09/2020)

Aceito em: (11/11/2020) 